\title{
Gastric pH Profile and Its Control in Fasting Beagle Dogs
}

\author{
Ichimaro Yamada, ${ }^{*}$ Hiroaki Mizuta, Tomoko Goda, Keiichiro Haga and Kenji OGawa \\ Research Laboratories, Yoshitomi Pharmaceutical Industries Ltd., 955 Koiwai, Yoshitomi-cho, Chikujo-gun. Fukuoka 871, Japan. \\ Received January 13, 1989
}

The gastric $\mathrm{pH}$ of fasting beagle dogs was measured by using an ion-selective field effect transistor pH sensor. In addition, a novel procedure to control the gastric $\mathrm{pH}$ in fasting beagle dogs was investigated. Inter- and intra-day variations in the gastric $\mathrm{pH}$ of the dogs were observed. The gastric $\mathrm{pH}$ of the dogs could be controlled by a single intravenous administration of omeprazole, an $\mathrm{H}^{+}, \mathrm{K}^{+}$-adenosine triphosphatase (ATPase) inhibitor (1 $\mathrm{mg} / 0.25 \mathrm{ml} / \mathrm{kg}$ ). The $\mathrm{pH}$ in the stomach was $6.6 \pm 0.2($ mean \pm S.D., $n=6)$ at $1 \mathrm{~h}$ after the omeprazole treatment, and this level of $\mathrm{pH}$ was maintained for a period of at least $3 \mathrm{~h}$. Beagle dogs in which the gastric $\mathrm{pH}$ has been controlled by omeprazole are considered to be useful as an animal model to be used for the pharmaceutical evaluation of drugs in subjects with a low acidity level.

Keywords beagle dog; ion-selective field effect transistor $\mathrm{pH}$ sensor; gastric $\mathrm{pH}$; omeprazole; gastric $\mathrm{pH}$ control

It is known that the bioavailability of a drug which is administered in the form of a pH-dependent release preparations affected by the gastrointestinal $\mathrm{pH}$, especially the gastric $\mathrm{pH}$. In fact, several early studies demonstrated that the bioavailability of diazepam, ${ }^{11}$ indomethacin, ${ }^{21}$ metronidazole $^{3)}$ and cinnarizine ${ }^{4)}$ from preparations exhibiting $\mathrm{pH}$ dependent dissolution was significantly affected by the gastric $\mathrm{pH}$ of the human individuals. Clinically, such variation in the drug bioavailability often causes individual differences in drug efficacy and safety. Accordingly, it is necessary to develop pharmaceutical preparations the drug bioavailability from which is not affected by the gastric $\mathrm{pH}$.

Beagle dogs are commonly used as a model species for the evaluation of the drug bioavailability because of the easiness of their handling. But, the bioavailability in beagle dogs differs considerably from that in humans because of species differences in gastrointestinal physiology, e.g., gastric $\mathrm{pH}$ and gastric emptying rate. The gastric $\mathrm{pH}$ in fasting beagle dogs has so far been measured by a radiotelemetric $^{5-7)}$ or an intubation method. ${ }^{8}$ However, there is a slight discrepancy between the results obtained by these two methods. Nakata et al. ${ }^{9)}$ and Ninai et al. ${ }^{10)}$ announced that they had controlled the gastric $\mathrm{pH}$ of beagle dogs at a high acidity level (less than $\mathrm{pH} 2.0$ ) by intramuscular administration of pentagastrin. However, a procedure for controlling and maintaining the gastric $\mathrm{pH}$ at a low acidity level (higher than $\mathrm{pH}$ 6.0) has been established for rabbits, ${ }^{11)}$ but not for beagle dogs.

In the present study, an ion-selective field effect transistor $\mathrm{pH}$ sensor which was developed for the accurate and continuous measurement of a small $\mathrm{pH}$ change in the blood $\mathrm{pH}$ in arteries and veins ${ }^{12)}$ was applied to measurements of gastric $\mathrm{pH}$ in fasting beagle dogs. In addition, this paper describes a method for controlling and maintaining the gastric $\mathrm{pH}$ of beagle dogs at a low acidity level by intravenous administration of omeprazole, an $\mathrm{H}^{+}, \mathrm{K}^{+}$adenosine triphosphatase (ATPase) inhibitor.

\section{Experimental}

Materials Omeprazole (( \pm$)$-5-methoxy-2-[[(4-methoxy-3,5-dimethyl2-pyridyl)methyl]sulfinyl]benzimidazole) was used as received from AB Hässle, Sweden. All other chemicals were standard commercial products of analytical grade.

Animals Six healthy 2-year-old male beagle dogs weighing 9.5 to

$11.0 \mathrm{~kg}$ were used after being fasted overnight. All dogs were allowed free access to water, but no food was given until the experiment was finished. Measurement of the Gastric pH in Fasting Beagle Dogs A KR $-500 \mathrm{pH}$ $\mathrm{pCO}_{2}$ Monitor (Kuraray Co., Ltd., Japan) connected with an ion-selective field effect transistor $\mathrm{pH}$ sensor ( $\mathrm{pH}$ sensor) was used in these experiments. The $\mathrm{pH}$ sensor was placed in Teflon tubing $(6 \mathrm{~mm}$ in outside diameter, $4 \mathrm{~mm}$ in inside diameter, $70 \mathrm{~cm}$ long) in order to protect it from possible damage during the experimental period. The gastric $\mathrm{pH}$ was measured via the $\mathrm{pH}$ sensor inserted perorally into the stomach of conscious beagle dogs. Dissection of an anesthetized beagle dog revealed that the end of the Teflon tubing had reached in the stomach following insertion of a length of about $60-70 \mathrm{~cm}$. For each experiment, the $\mathrm{pH}$ sensor was calibrated using pH 1.68 and 6.86 standard buffer solutions. A detailed description of the geometry and fabrication of the $\mathrm{pH}$ sensor has been given by Bergveld. ${ }^{13}$,

Procedure for the Gastric pH Control The beagle dogs having a weakly acidic to neutral gastric $\mathrm{pH}$ (higher than $\mathrm{pH} 6.0$ ) were prepared by a single intravenous administration of omeprazole $(1 \mathrm{mg} / \mathrm{kg})$. Omeprazole was dissolved in the mixture of polyethylene glycol 400 and $1 \%$ sodium hydrogencarbonate $(1: 1, \mathrm{v} / \mathrm{v})$ within an hour before injection, and the concentration of omeprazole was adjusted to $4 \mathrm{mg} / \mathrm{ml}$.

\section{Results and Discussion}

A typical gastric $\mathrm{pH}$-time profile obtained in a fasting beagle dog by measuring the $\mathrm{pH}$ with the $\mathrm{pH}$ sensor is shown in Fig. 1. The gastric $\mathrm{pH}$ of beagle dog varied irregularly during a short period. This $\mathrm{pH}$ sensor thus enables us to make successive measurement of the gastric $\mathrm{pH}$ of beagle dogs by persistently placing it in the stomach. In the present study, however, the sensor was inserted into the stomach at each time of measurement.

Figure 2 shows intraday variations in the gastric $\mathrm{pH}$ in fasting beagle dogs $(n=6)$. Measurement was carried out at $9: 00,11: 00,13: 00,15: 00$ and 17:00. Wide intra- and inter-individual variations ranging from $\mathrm{pH} 0.9$ to 7.0 were observed. Figure 3 shows the result of the day-to-day measurement of gastric $\mathrm{pH}$. The experiments were repeated

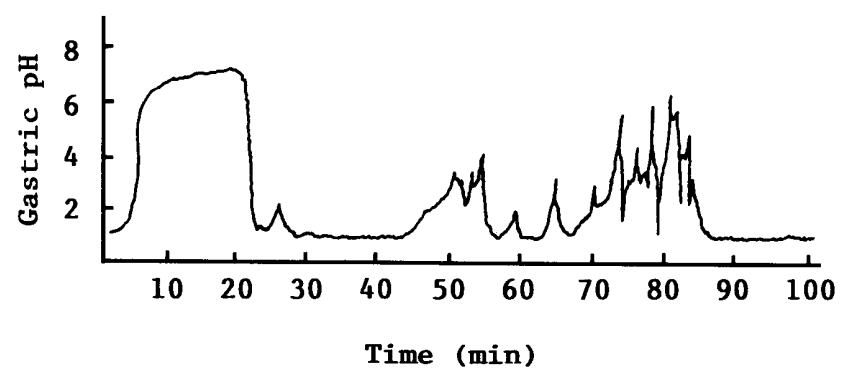

Fig. 1. Typical Gastric pH-Time Profile in Fasting Beagle Dog as Measured by the Ion-Selective Field Effect Transistor pH Sensor 


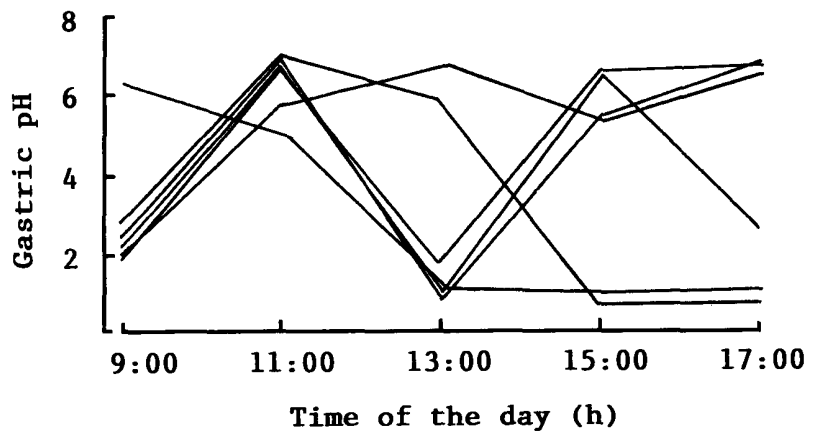

Fig. 2. Intra-day Variation of Gastric pH in Fasting Beagle Dogs $(n=6)$

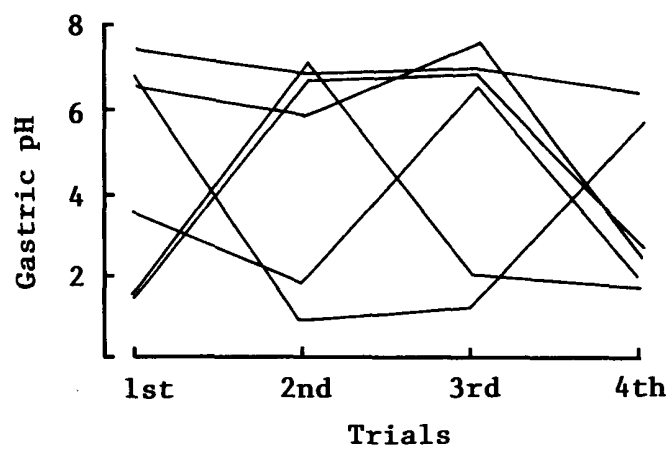

Fig. 3. Inter-day Variation of Gastric $\mathrm{pH}$ in Fasting Beagle Dogs $(n=6)$

4 times during two weeks. The mesurement was carried out at 9:00 for each trial. The gastric $\mathrm{pH}$ of beagle dogs was most variable in the fasting state. There was no consistent pattern in inter-day variations.

We have established a rapid and accurate method for measurement of the gastric $\mathrm{pH}$ using the ion-selective field effect transistor $\mathrm{pH}$ sensor. The results obtained by this method were in agreement with those obtained by the intubation method $^{8)}$ rather than by the radiotelemetric method. ${ }^{5.6)}$

It was found in the present study using the ion-selective field effect transistor $\mathrm{pH}$ sensor that the gastric $\mathrm{pH}$ of beagle dogs was variable. Accordingly, the beagle dog is not a suitable animal species for the evaluation of the bioavailability of drugs and dosage forms whose dissolution may be influenced by the gastric $\mathrm{pH}$. To evaluate the relationship between the bioavailability and physicochemical properties of drugs or formulation characteristics, it is necessary to establish an accurate method for controlling the gastric $\mathrm{pH}$. Omeprazole, a substituted benzimidazole, has a potent and long-lasting inhibitory effect on basal and stimulated gastric secretion. ${ }^{14)}$ It rapidly raises the gastric $\mathrm{pH}$ of patients with in duodenal ulcers and maintains the gastric $\mathrm{pH}$ at higher than 4.0 for a long time after intravenous administration at a dose of $\left.1 \mathrm{mg} / \mathrm{kg} .{ }^{15}\right)$ On the basis of this finding, we chose $1 \mathrm{mg} / \mathrm{kg}$ as the dose to be used in the present experiment. Figure 4 shows the gastric $\mathrm{pH}$ versus time curve before and after intravenous administration of omeprazole at a dose of $1 \mathrm{mg} / \mathrm{kg}$ in the fasting state. The measurement were carried out immediately before and at $0.5,1,2,4,6$ and $8 \mathrm{~h}$ after administration. A wide variation in the gastric $\mathrm{pH}$ was not found at $1 \mathrm{~h}$ after the omeprazole administration, and the gastric $\mathrm{pH}$ was

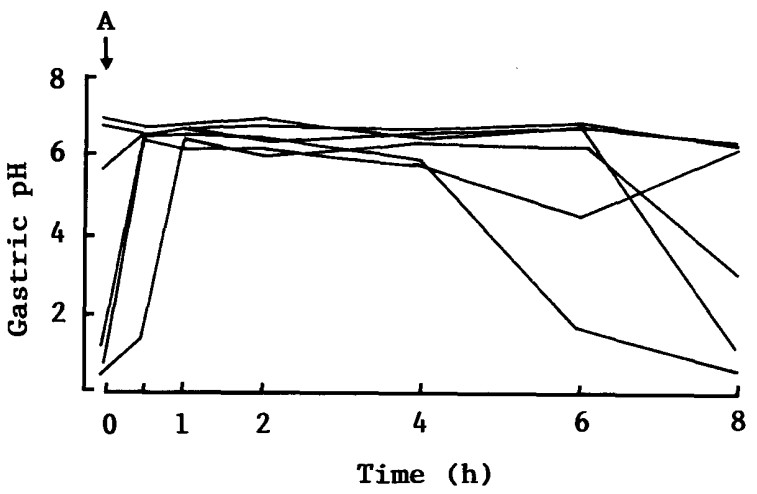

Fig. 4. Gastric pH-Time Profile after Intravenous Administration of Omeprazole in Fasting Beagle Dogs $(n=6)$

A: omeprazole $1 \mathrm{mg} / \mathrm{kg}$, i.v.

$6.6 \pm 0.2$ (mean \pm S.D., $n=6$ ). This level of $\mathrm{pH}$ was maintained consistently until $4 \mathrm{~h}$ after the intravenous administration of omeprazole.

It has been suggested that expulsion of large indigestible objects from the stomach is dependent on the interdigestive migrating myoelectric complex (IMMC) termed the "housekeeper wave"." This wave occurs at about 1.5$2 \mathrm{~h}$ intervals in fasting dogs. ${ }^{16)}$ Accordingly, the effect of the gastric $\mathrm{pH}$ on drug absorption must be largest during the first $2 \mathrm{~h}$ after oral administration of the drug. The present study revealed that the gastric $\mathrm{pH}$ of beagle dogs was controlled at a level of $\mathrm{pH} 6$ or higher for a period of at least $3 \mathrm{~h}$ by intravenous administration of omeprazole. This method makes it possible to evaluate exactly the effect of the gastric $\mathrm{pH}$ on drug absorption. Earlier studies have demonstrated that the gastric $\mathrm{pH}$ of beagle dogs was controlled at $\mathrm{pH} 2$ or lower by intramuscular administration of pentagastrin. ${ }^{9,10)}$ However, pentagastrin delays gastric emptying and increases the frequency of antral and duodenal slow waves in dogs. ${ }^{17)}$ On the other hand, omeprazole had no significant effect on the gastric emptying of solids or liquids or on several phases of myoelectric activity in the stomach in the fasting state. ${ }^{18)}$

The beagle dog has not been considered to be a suitable animal species for the pharmaceutical evaluation of weakly basic and weakly acidic drugs. However, gastric $\mathrm{pH}$ controlled beagle dogs are considered to be useful as an animal model to estimate the bioavailability of drugs and formulations with $\mathrm{pH}$-dependent dissolution profiles at a low acidity level.

\section{References}

1) H. Ogata, N. Aoyagi, N. Kaniwa, T. Shibazaki and A. Ejima, Int. J. Clin. Pharmacol. Ther. Toxicol., 20, 166 (1982).

2) N. Aoyagi, H. Ogata, N. Kaniwa and A. Ejima, Int. J. Clin. Pharmacol. Ther. Toxicol., 23, 469 (1985).

3) H. Ogata, N. Aoyagi, N. Kaniwa, T. Shibazaki, A. Ejima, Y. Takagishi, T. Ogura, K. Tomita, S. Inoue and M. Zaizen, Int. J. Pharmaceut., 23, 277 (1985).

4) H. Ogata, A. Aoyagi, N. Kaniwa, A. Ejima, N. Sekine, M. Kitamura and Y. Inoue, Int. J. Pharmaceut., 29, 113 (1986).

5) C. Y. Lui. G. L. Amidon, R. R. Beradi, D. Fleisher, C. Youngheerg and J. B. Dressman, J. Pharm. Sci, 75, 271 (1986).

6) J. B. Dressman and G. L. Amidon, J. Pharm. Sci., 73, 935 (1984).

7) T. Itoh, T. Higuchi, C. R. Gardner and L. Caldwell, J. Pharm. Pharmacol., 38, 801 (1986).

8) H. Ogata, N. Aoyagi, N. Kaniwa, A. Ejima, T. Kitaura, T. Ohki and 
K. Kitamura, Int. J. Pharmaceut., 29, 121 (1986); N. Aoyagi, H. Ogata, N. Kaniwa, A. Ejima, H. Nakata, J. Tutumi, T. Fujita and I. Amada, Int. J. Clin. Pharmacol. Ther. Toxicol., 23, 578 (1985).

9) H. Nakata, S. Tanaka, J. Tutumi, S. Ida, Y. Miyake, H. Ichiki, K. Tasaka and H. Orima, The 2nd Annual Meeting of the Academy of Pharmaceutical Science and Technology, Japan, 1985, III-2, p. 65.

10) T. Ninai, K. Hoshiyama, K. Sasahara, H. Ogata and N. Aoyagi, The 3rd Annual Meeting of the Academy of Pharmaceutical Science and Technology, Japan, 1987, IV-9, p. 134.

11) Takahashi, M. Mori, Y. Uezono, H. Fujioka and Y. Imasato, Yakuzaigaku, 43, 187 (1983).

12) K. Shimada, M. Yano, K. Shibatani, Y. Komoto, M. Esashi and T. Matsuo, Med. and Biol. Eng. and Comput., 18, 741 (1980); S. J. Schepel, N. F. de Rooiji, G. Knoning, B. Oeseburg and W. G. Zijlstra, ibid., 22, 6 (1984).
13) D. Bergveld, Med. and Biol. Eng. and Comput., 17, 655 (1979).

14) T. Lind, C. Cederberg, G. Ekenveld, U. Hanglund and L. Olbe, Gut, 24, 270 (1983); B. Wallmark, P. Lorentzon and H. Larsson, Scand. J. Gastroenterol., 20 (suppl 108), 37 (1985).

15) R. P. Walt, J. R. Reynolds, M. J. S. Langman, H. L. Amart, G. Kitchingman, K. W. Somerrville and C. J. Hawkey, Gut, 26, 902 (1985).

16) R. C. Gill, M-A. Pilot, P. A. Thomas and D. L. Wingate, Am. J. Physiol., 249, G665 (1985).

17) R. R. Dozois and K. A. Kelly, Am. J. Physiol., 221, 113 (1971); A. R. Cooke, T. E. Chvasta and N. W. Weisbrodt, ibid., 223, 934 (1972).

18) M. Horowitz, D. J. Hetzel, P. J. Buckle, B. E. Chatterton and D. J. C. Shearman, Br. J. Clin. Pharmacol., 18, 791 (1984); S. A. Pederson, K. Kraglund and L. Vinter-Jensen, Scand. J. Gastroenterol., 22, 725 (1987). 